\title{
Adaptive capacity and water governance in the Keiskamma River Catchment, Eastern Cape Province, South Africa
}

\author{
Kevin Grecksch ${ }^{1 *}$ \\ University of Oldenburg, Department of Economics and Law, Ammerländer Heerstraße 114-118, 26129 Oldenburg, Germany
}

\begin{abstract}
South Africa, being a semi-arid country, faces water resource constraints. The projected impacts of climate change in the Keiskamma River Catchment, Eastern Cape Province, are, for example, changes in rainfall with effects on streamflow, salt water intrusion, decreasing water quality due to runoff and erosion, and droughts. This paper uses an existing framework, the Adaptive Capacity Wheel (ACW), complemented by two additional dimensions: adaptation motivation and adaptation belief. The objectives were, first, to assess the adaptive capacity of water governance in the study region, and, second, to show how the ACW can be used as an approach and a communication tool with stakeholders to identify strengths and weaknesses. Based on this, recommendations can be drawn that could help water experts and stakeholders in the future. The results depict a 'medium' score for adaptive capacity. However, it is important to look closely at each dimension assessed by the ACW. The key recommendations are: to overcome the implementation gap, to ensure better coordination across and within governmental levels; to raise awareness, capacity and skill among decision makers and the public; and to increase the political will to overcome adaptation barriers.
\end{abstract}

Keywords: adaptive capacity, Adaptive Capacity Wheel (ACW), climate change adaptation, South Africa, water governance

\section{INTRODUCTION}

Climate change in South Africa will result in changing rainfall patterns, the intensity of storms and the extremes of droughts and floods; increasing evaporation; changes in soil moisture and runoff and thus water availability; changing water quality conditions (including temperature of aquatic systems) and increasing climate variability' (Department of Water Affairs, 2013 p. 75). These projected impacts pose severe challenges to municipalities. Hence, multiple and flexible adaptation measures and solutions are needed that take into account regional and local ecological, economic and social circumstances. Furthermore, these measures need to address the issue of uncertainty, which is closely linked to the climate change adaptation debate. Also closely linked to the climate change debate is the issue of development. The potential impacts of climate change may exacerbate existing developmental challenges and climate change adaptation competes with other pressing challenges such as economic development, high unemployment, food insecurity and high levels of poverty. Because of the close relationship between these challenges and climate change it is important to formulate integrated policies.

The research objectives were twofold: firstly, to assess the adaptive capacity of water governance in the Keiskamma Catchment with a focus on the Ngqushwa Local Municipality in the Eastern Cape Province, South Africa, applying an existing framework: the Adaptive Capacity Wheel (ACW) (Gupta et al., 2010; Gupta et al., 2008). This framework was complemented by two additional criteria: the motivation to adapt and adaptive capacity belief (Grothmann, 2005; Grothmann et al., 2013; Grothmann et al., 2005). In order to better understand the adaptive capacity results a small section describes the

\footnotetext{
* To whom all correspondence should be addressed. ๔ +49 441798 4797; e-mail: kevin.grecksch@uni-oldenburg.de Received 3 January 2014; accepted in revised form 13 March 2015
}

sensitivity of water governance in the study region. The second aim was to evaluate which lessons and recommendations can be drawn from the results. It is argued that the Adaptive Capacity Wheel can function as a communication tool to discuss strengths and weaknesses with experts and stakeholders, which can subsequently be the basis for future research and action (Grecksch, 2013). The water sector was chosen because it is identified by the South African Risk and Vulnerability Atlas (Department of Science and Technology, 2010) as one of the most sensitive sectors with regard to climate change. For the purpose of this paper, water governance is defined as the coordination, steering and managing of water across multiple levels. It is also defined as better coordination and information across sectors and policy fields accompanied with enhanced participation by civil society groups and water users (see Conca, 2006; Huitema et al., 2009; Pahl-Wostl, 2009; Teisman et al., 2013). Adaptive capacity is defined as 'the ability of a system to adjust to climate change (including climate variability and extremes), to moderate potential damages, to take advantage of opportunities, or to cope with the consequences' (IPCC, 2007 p. 869).

The paper starts with a discussion of the method used. This is followed by a brief description of the study area and the results from expert interviews, and literature and document analysis. The paper concludes with an assessment of the adaptive capacity of water governance in the study area and recommendations.

\section{METHODS}

\section{The Adaptive Capacity Wheel (ACW)}

There are almost no political science concepts and methods to systematically assess adaptive capacities of social systems, especially approaches that can be applied to different sectors such as water (Huntjens et al., 2012; Pahl-Wostl, 2009), but also spatial planning, flood protection, etc. A promising approach stems from Gupta et al. (2010), who presented 6 dimensions of 
institutional adaptive capacity: variety, learning capacity, room for autonomous change, leadership, availability of resources and fair governance. For institutions, Gupta et al. (2010) refer to the definition from the Project of the International Human Dimensions Programme: 'systems of rules, decision-making procedures, and programmes that give rise to social practices, assign roles to participants in these practices, and guide interactions among occupants of the relevant roles' (IDGEC Scientific Planning Committee, 1999 p. 14). According to Gupta et al. (2010), institutions that promote adaptive capacity: (i) encourage the involvement of a variety of perspectives, actors and solutions ('variety'); (ii) enable social actors to continuously learn and improve their institutions ('learning capacity'); (iii) allow and motivate social actors to adjust their behaviour ('room for autonomous change') ; (iv) can mobilize leadership qualities ('leadership'), (v) can mobilize resources for implementing adaptation measures ('availability of resources'), and (vi) enhance principles of fair governance ('fair governance').

'Variety' is defined by the incorporation of various actors, political/administrative levels, solutions and sectors. The presence of various perspectives on climate change prevents the establishment of a constricted framework, while the diversity of solutions provides options for a variety of developments, which is important in view of the uncertainty of prognoses and the complexity of climate impacts. 'Learning capacity' describes the ability of participating actors to learn. Are conclusions drawn from past experience and do actors regularly check their own assumptions? The ability to change and to drive change defines the 'room for autonomous change'. An important factor here is whether current activities are being evaluated. The 'leadership' dimension raises the question of whether leadership and incentives are present. Furthermore, the questions here are whether individual actors can move climate adaptation forward through their own commitment, and whether the institutional structure allows the formation of coalitions and networks. 'Resources' are defined as the presence of funding, sufficient personnel and the possibility of implementing one's objectives. The 'fair governance' dimension asks whether the rules are fair and transparent, and whether participation is possible. Fair governance therefore upholds basic democratic principles and fairness (Gupta et al., 2010; Gupta et al., 2008).

Since the approach by Gupta et al. $(2010 ; 2008)$ reflects the perspectives and perceptions of those actors who make decisions about the realisation of adaptation measures at only a small scale, two more dimensions, rooted in psychology literature, were added. In order to address important psychological determinants of adaptive capacity, 'adaptation motivation' and 'adaptation belief' were also included in an extended version of the ACW (Grothmann, 2005; Grothmann et al., 2013; Grothmann et al., 2005). Figure 1 shows the extended Adaptive Capacity Wheel (ACW). 'Adaptation motivation' refers to the motivation of decision makers and other actors to realise, support and/or promote adaptation to climate change. The main determinant of 'adaptation motivation' is the perception of risks and opportunities of climate change. Perceptions of climate change risks and climate change opportunities have been shown to be important determinants of adaptation in various empirical studies (e.g. Grothmann et al., 2005; Weber, 1997).

'Adaptation belief' refers to the ability of actors and decision makers to be able to adapt to climate change. The objective ability or capacity of a human actor (what an individual, a group, or a culture could do, indicated by the availability and access to resources) only partly determines if an adaptive response is taken. Equally important is the subjective or

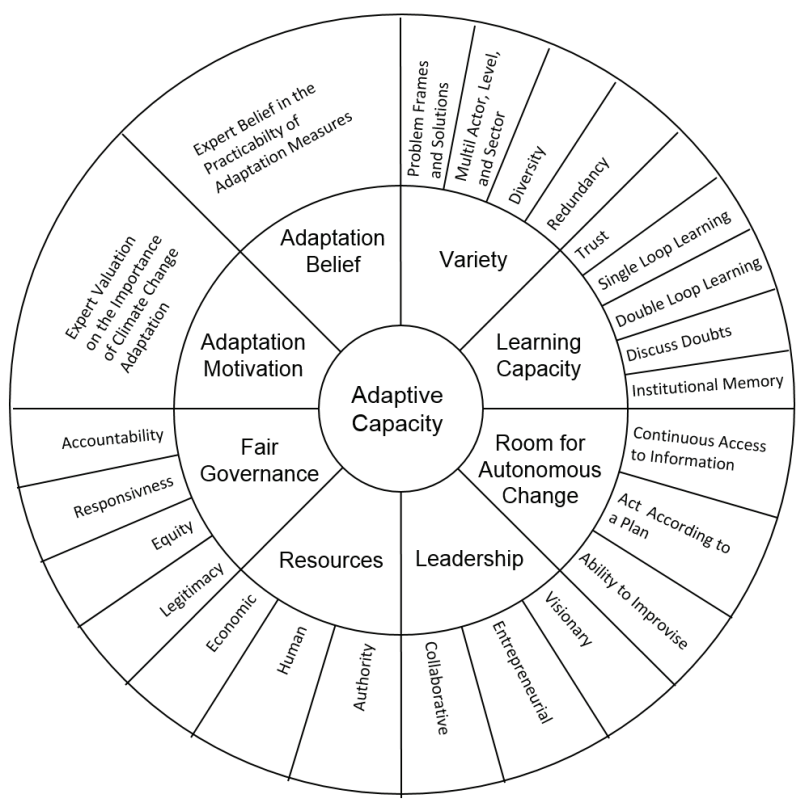

Figure 1

Adaptive Capacity Wheel (extended after Gupta et al., 2008, 2010)

perceived ability of human actors because the subjective ability can be very different from the objective ability. People and decision makers can underestimate and overestimate their action scope and studies show that low adaptation beliefs can become barriers to adaptation of private households, for instance (Grothmann et al., 2005). Hence, there could be a systematic bias towards underestimating the capacity to adapt successfully to climate change impacts (Grothmann et al., 2013; Grothmann et al., 2011).

By this it is not being proposed that objective aspects of adaptive capacity - like the financial resources or institutional entitlements - are insignificant determinants of adaptive capacity and adaptation. They are included in the ACW under the resources dimension, but if agents systematically underestimate their own ability to adapt then this qualifies as a more important 'bottleneck' for adaptation than the objective constraints (Grothmann et al., 2013; Grothmann et al., 2011).

\section{Data collection and analysis}

The literature review included scientific studies that have already been conducted to assess potential impacts of climate change in the Eastern Cape Province. These studies were systematically reviewed, especially with regard to results and conclusions relating to climate change in the region. No study as yet has assessed the adaptive capacity of water governance in the study region. The document analysis included reviewing governmental documents, i.e., formal and informal written documents relevant to the study region, such as official governmental reports, laws and regulations from the three tiers of government in South Africa (see Table 1).

Four experts were also interviewed between June and September 2013 (see Table 1). The interview subjects were identified based on an analysis of relevant organisations in water governance, such as district water departments, and bulk water suppliers in the focus area but also for the Eastern Cape Province in general. Interview requests were also made to the Department of Water Affairs (DWA) Regional Office, 


\begin{tabular}{|c|c|}
\hline \multicolumn{2}{|c|}{$\begin{array}{c}\text { Table } 1 \\
\text { List of interviews and documents used }\end{array}$} \\
\hline Interviews & Interviewee* \\
\hline Interview W1 - Amatola Water & $\begin{array}{l}\text { Nikite Muller (Environmental Specialist) } \\
\text { Sieg Rousseau (Water Resources Manager) }\end{array}$ \\
\hline Interview W2 - Coastal \& Environmental Services (CES) & Alan Carter (Director) \\
\hline $\begin{array}{l}\text { Interview W3 - Eastern Cape Provincial Government - Department of } \\
\text { Economic Affairs, Environmental Development and Tourism }\end{array}$ & Lyndon Mardon (Manager) \\
\hline \multicolumn{2}{|l|}{ Documents (Reference) } \\
\hline \multicolumn{2}{|l|}{$\begin{array}{l}\text { National Water Act (Act No } 36 \text { of 1998) } \\
\text { (RSA, 1998) }\end{array}$} \\
\hline \multicolumn{2}{|l|}{$\begin{array}{l}\text { Water Services Act (No. } 108 \text { of 1997) } \\
\text { (RSA, 1997) }\end{array}$} \\
\hline \multicolumn{2}{|l|}{$\begin{array}{l}\text { National Water Resource Strategy } 2 \\
\text { (Department of Water Affairs, 2013) }\end{array}$} \\
\hline \multicolumn{2}{|l|}{ (Department of Science and Technology, 2010) } \\
\hline \multicolumn{2}{|c|}{$\begin{array}{l}\text { National Climate Change Response - Green Paper } \\
\text { (RSA, 2009) }\end{array}$} \\
\hline \multicolumn{2}{|c|}{$\begin{array}{l}\text { Department of Environmental Affairs - Governance of Climate Change in South Africa } \\
\text { (Department of Environmental Affairs, 2011) }\end{array}$} \\
\hline \multicolumn{2}{|c|}{$\begin{array}{l}\text { WRC Report No. TT 518/12 - A } 2011 \text { Perspective On Climate Change And The South African Water Sector } \\
\text { (Schulze, 2012) }\end{array}$} \\
\hline \multicolumn{2}{|c|}{$\begin{array}{l}\text { Eastern Cape Climate Change Response Strategy } \\
\text { (Eastern Cape Department of Economic Development and Environmental Affairs, 2011) }\end{array}$} \\
\hline \multicolumn{2}{|c|}{$\begin{array}{l}\text { Eastern Cape Provincial Water Sector Plan }(2007-2012) \\
\text { (Department of Water Affairs and Forestry, 2006) }\end{array}$} \\
\hline \multicolumn{2}{|c|}{$\begin{array}{l}\text { Eastern Cape Planning Commission Vision } 2030 \text { - A Diagnostic Report On Environmental Sustainability In The Eastern Cape } \\
\text { (Eastern Cape Planning Commission, 2013) }\end{array}$} \\
\hline \multicolumn{2}{|c|}{$\begin{array}{l}\text { Amathole District Municipality - Integrated Development Plan 2013-14 } \\
\text { (Amathole District Municipality, 2013) }\end{array}$} \\
\hline \multicolumn{2}{|c|}{$\begin{array}{l}\text { Amathole District Municipality - Climate Change Risk and Vulnerability Assessment } \\
\text { (Amathole District Municipality, 2011) }\end{array}$} \\
\hline $\begin{array}{l}\text { Ngqushwa Local Municipality - Integrated Development Plan 2013-14 } \\
\text { (Ngqushwa Local Municipality, 2013) }\end{array}$ & \\
\hline
\end{tabular}

${ }^{*}$ Interviews W1, W2, W3 were conducted in person, Interview W3 was sent and returned via e-mail. All interviews are quoted as '(Interview W'Number')'.

Amathole District Municipality and environmental NGOs, but these either remained unanswered or follow-up communication remained unanswered. The semi-structured interviews lasted for 1 to 1.5 hours and were conducted based on focused, problem-centred and expert interview methods (see Fowler et al., 1990; Merton et al., 1946; Meuser et al., 1991; Witzel, 1985; Witzel, 2000). These methods restrict the information that is expected from respondents more than other interview techniques, but are sufficiently open to allow respondents to name aspects that are not addressed in the interview guideline. The interview guideline included questions regarding the sensitivity and adaptive capacity of water governance. The interviews were partly transcribed.

The collected literature, documents and transcribed interviews were analysed using a qualitative content analysis method (Mayring, 2008) to generate assessments of the sensitivity and adaptive capacity of water governance in the Keiskamma River Catchment. To guarantee comparability and reliability of data analysis, the assessments were reviewed by another assessor based on the same evaluation criteria and then discussed to generate an assessment agreement.

\section{Assessment of sensitivity and adaptive capacity}

To assess the adaptive capacity of water governance, the expert interviews explicitly included questions on adaptation motivation, capacity belief, learning capacity and room for autonomous change. Due to the restricted time of the interviews, not all dimensions of adaptive capacity were explicitly addressed in the interviews. The literature review and document analysis addressed all eight dimensions of adaptive capacity.

To be able to communicate the results more clearly, an extended version of the Adaptive Capacity Wheel by Gupta et al. (2010) (see Fig. 1) was used. The inner circle of the wheel assesses adaptive capacity as a whole, the middle circle the dimensions and the outer circle the criteria. The six dimensions of adaptive capacity described by Gupta et al. (2010), and their criteria, were rated on a 5-level scale (very high, high, medium, low, very low), whilst 'adaptation motivation' and 'capacity belief' were rated on a 4-level scale (no, low, medium, high). The reason for the different scales was to avoid a medium level, which interviewees like to select if unsure or if they do not want to decide. In addition, it was also difficult to develop complete 

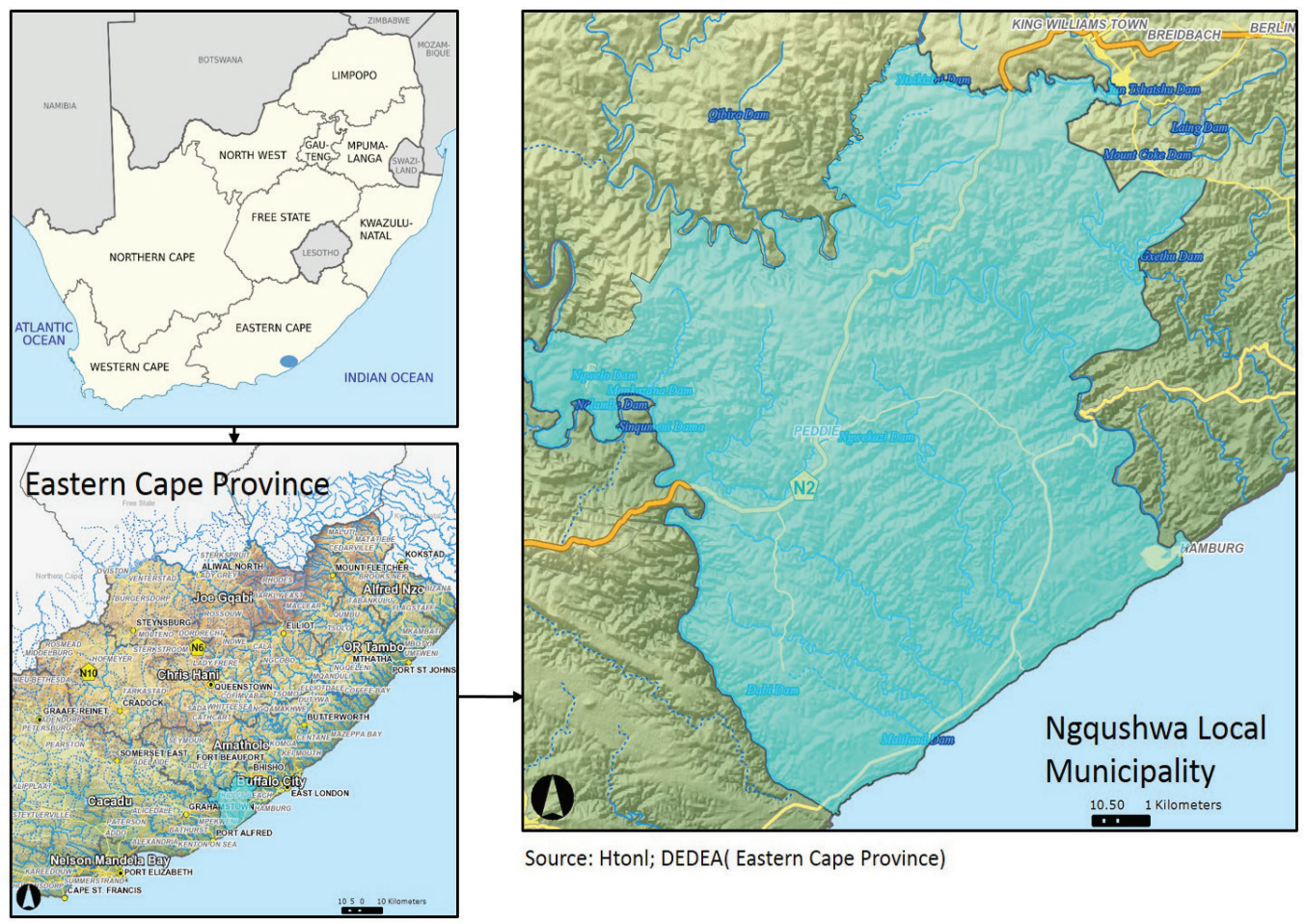

Source: Htonl; DEDEA( Eastern Cape Province)

Figure 2

Ngqushwa Local Municipality (Source: Htoni; Department of Economic Development, Environmental Affairs and Tourism, Eastern Cape Province)

verbalised scales (i.e. written scales for every level) for a 5-level scale for the questions used in the interviews. To assess the six 'Gupta-dimensions', numbers between 1 (very low) and 5 (very high) were assigned to evaluate each indicator.

In the next stage, an average was calculated for each dimension based on all criteria belonging to the respective dimension. The average values were rounded up or down (for instance values between 2.50 and 3.49 were rounded to 3 ). In a last stage, the numerical values were replaced with verbal values and colours: $5=$ very high (dark green); $4=$ high (light green); $3=$ medium (yellow); $2=$ low (orange); and $1=$ very low (red). To assess the overall adaptive capacity, each 'Gupta-dimension' was assigned a value between 1 to 5 , whilst values from 1 to 4 were assigned to the assessment of adaptive capacity belief and adaptation motivation. These values were then normalised (meaning the values for the six 'Gupta-dimensions' were divided by 5 and the values for adaptive capacity belief and adaptation motivation were divided by 4) in order to achieve the same weighting for all eight dimensions. In a last step, the normalised values for all eight dimensions were added and divided by eight. Results between 0 and 0.33 were valued as 'low' adaptive capacity, values between 0.34 and 0.66 were valued as 'medium' adaptive capacity, and values between 0.67 and 1 as 'high' adaptive capacity.

\section{RESULTS}

\section{Study area: Ngqushwa Local Municipality (Keiskamma River catchment), Eastern Cape Province, South Africa}

The Keiskamma River Catchment was selected as the study region against the background of the research project ClimA-Net (www.climanet.uni-oldenburg.de) where it is one of two study areas. In this paper, special attention was given to the area encompassing the Ngqushwa Local Municipality
(NLM), which is situated in the Amathole District Municipality (ADM). The NLM covers an area of approximately $2245 \mathrm{~km}^{2}$, consists of 118 villages, and is divided into 13 wards. An estimated 72190 people inhabit the municipality (Ngqushwa Local Municipality, 2013). It is a rural area and was part of the former homeland of the Ciskei. Land use is predominantly livestock farming and subsistence agriculture. $99 \%$ of the inhabitants are African and the unemployment rate was $52.8 \%$ in 2011.

Only $6.1 \%$ of the population has access to piped water inside their dwelling and $51.5 \%$ use a pit toilet without ventilation compared to $4.7 \%$ using a flush toilet connected to sewerage system (Ngqushwa Local Municipality, 2013; Statistics South Africa, 2013). In addition, the municipality is characterised by different levels of elevation. Increased soil erosion is caused by poor management and overgrazing, and also by an invasive alien plant (Pteronia incana, which causes soil crusting) (Mhangara et al., 2012).

\section{Sensitivity}

The expert interviews tried to elicit information about the sensitivity of water governance by using the following complex question: 'Which of the current water governance measures in the region would not be sufficient to make use of potential opportunities and avoid potential risks related to climate change?' Sensitivity only played a minor role in this study since the focus of the study is on adaptive capacity. Nevertheless, for a better understanding, the water sector's sensitivity is summarised briefly. Sensitivity is here understood as: 'the degree to which a system is affected, either adversely or beneficially, by 'climate variability' or change. The effect may be direct (e.g. a change in crop yield in response to a change in the mean, range or variability of temperature) or indirect (e.g. damages caused by an increase in the frequency of coastal flooding due to 
sea-level rise)' (IPCC, 2007 p. 881). The assessment is based, as mentioned above, on expert interviews, document and literature analysis (see 'Methods').

According to the Eastern Cape Province's Climate Change Response Strategy (Eastern Cape Department of Economic Development and Environmental Affairs, 2011), the sensitivity of the Eastern Cape Province is characterised by rising sea level, altered rainfall patterns, higher temperatures, and more frequent or intense extreme weather events including heat waves, droughts, storms and floods. Respondents also said that, generally speaking, the west of the province will become drier and the east of the province will become wetter (Interview W2, W3). In addition one interviewee mentioned: 'There will be more serious storm events going into the future' (Interview W3). Diseases such as rift valley fever affecting cattle, flood damage, vulnerable coastlines and wildfires were also mentioned as potential impacts (Interview W2). Experts also stressed that changing rainfall patterns (season and frequency) are already visible (Interviews W1, W2) and the representatives from bulk water supplier Amatola Water said that assuring water quantity and quality will become a challenge (Interview W1).

The Amathole District Municipality describes climatic trends in its Climate Change Risk and Vulnerability Assessment and Response Framework (Amathole District Municipality, 2011) and in its Integrated Development Plan (Amathole District Municipality, 2013). By referring to the former it states that: 'temperatures will increase by $2.1-2.2^{\circ} \mathrm{C}$ inland and $1.5-1.7^{\circ} \mathrm{C}$ along the coast by 2045 . Rainfall patterns will become more concentrated into heavy falls or floods and longer dry periods. Spring will be wetter than summer, i.e., in spring rainfall will increase about 10 to $12 \mathrm{~mm}$ towards the coast and in summer will increase about 2 to $4 \mathrm{~mm}$ per annum inland. Average sea levels are likely to rise by roughly $2.5 \mathrm{~cm}$ every 10 years.' (Amathole District Municipality, 2013 p. 39). Furthermore, projected impacts for the water sector in the ADM are described. This includes 'increased variability and intensity of stormflow and dry-spells/droughts; reduced median annual streamflow; increased cost of water services e.g. $10 \%$ decline in run-off could double the cost of new water schemes; reduced predictability of weather, more intense floods and increased return period for flooding' (Amathole District Municipality, 2013 p. 40).

\section{Adaptive capacity}

'Water is arguably the primary medium through which early (and subsequent) climate change impacts will be felt by people, ecosystems and economies', writes Schulze (2012 p. 4), stressing the importance of the water sector in South Africa. In his comprehensive study he identifies 17 water-related sectors that will be affected by water-related climatic changes, thereby further emphasising the need for adaptation (Schulze, 2012). However, the current status of South Africa's water sector has been characterised by capacity constraints, inadequate funding, a reliance on ageing bulk infrastructure and erratic water quality, especially in smaller municipalities and rural areas (Stuart-Hill et al., 2010). Various studies indicate that South Africa's water sector is not well prepared with regard to climate change adaptation, especially at the local level and with regard to the institutional arrangements (Department of Environmental Affairs, 2011; Department of Science and Technology, 2010; Madzwamuse, 2010; Ncube et al., 2013; Schreiner, 2009; Smith, 2009).
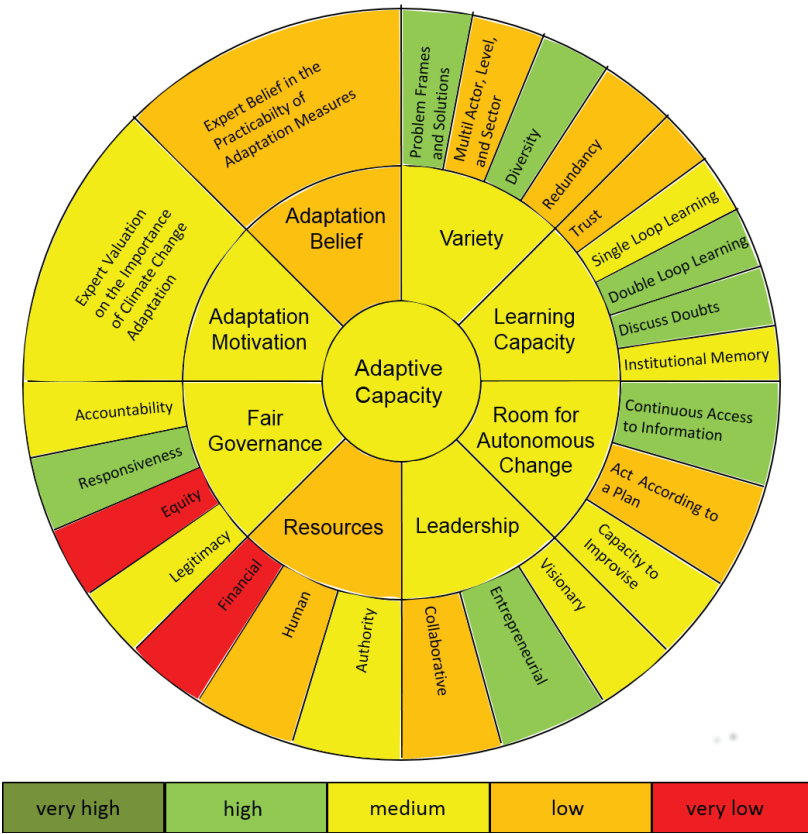

Figure 3

Adaptive Capacity Wheel for water governance in the Keiskamma River catchment (extended after Gupta, 2008, 2010)

In the following sections, results (based on expert interviews, document and literature analysis) for each dimension of the ACW are presented. Figure 3 presents the Adaptive Capacity Wheel for water governance in the study region. In the sense of a strength and weakness profile, the ACW shows which strengths could be used to develop adaptation strategies or which strengths could be built upon when implementing an adaptation measure (green). It also shows which weaknesses need to be addressed and improved (red and orange). These qualitative assessments represent an averaged evaluation of the adaptive capacity.

\section{Variety}

For the Keiskamma River Catchment, the variety dimension was scored 'medium'. In terms of 'problem frames and solutions', the National Water Resource Strategy (WRS) (Department of Water Affairs, 2013) delivers a binding problem definition for all tiers of government and all actors in the water sector, by outlining key concepts, strategies and challenges. The National Water Act (NWA) (RSA, 1998) and the Water Services Act (WSA) (RSA, 1997) form the basis of water legislation in South Africa. Integrated development plans (IDP) as well as water services development plans have to be prepared by every municipality. Since they have to be revised and updated regularly, it makes them flexible policy documents. The criterion 'multi-actor, multi-level, multi-sector', which is defined as involvement of different actors, levels and sectors in the governance process was rated 'low'. The analysed strategies and plans describe the necessary actors but there are deficits with regard to water user associations (WUA), for example. Ncube (2013) states that South Africa has recognised the challenges of climate change but not at the local level. The impacts are not immediate resulting in inaction and lack of appreciation, also caused by insufficient knowledge. A paper by the Department of Environmental Affairs (2011) on the governance of climate change described vertical coordination in South Africa as a 
huge problem in general and the relationship between district and local municipalities as lacking integration and coordination and becoming more and more competitive and hierarchical, with poor communication (see also Madzwamuse, 2010). The recommendation in the Amathole District Municipality Climate Change Risk and Vulnerability Assessment (2011 p. 51) is: 'ADM should aim to achieve vertical coordination from local municipality to nation, and horizontal coordination with other key stakeholders relevant to the district.'

The array of instruments and solutions, and thus the 'diversity', is high. Measures exist but deficits can be found when it comes to implementing measures. Here, a lack of skills and capacity as well as a lack of awareness were expressed by interviewees. In terms of 'redundancy', i.e., overlapping measures and possible synergies can hardly be found or are at a very early stage.

\section{Learning capacity}

'Trust' is a key issue for learning processes and a key element to collaboration. All interviewees stated that they collaborate with various actors from the government or civil society (Interviews W1, W2, W3). However, they also said that there are noncooperative actors and the people in charge of water affairs lack the right skills (Interview W1, W2). Hence 'trust' was scored 'low'. 'Single-loop learning' (the willingness to learn from past experiences) was scored 'medium', as IDPs for example are regularly updated.

As changing rainfall patterns are already experienced, Amatola Water has started to adjust its dam management and is now conducting its water supply planning process earlier in the year than they used to (Interview W1). The Amathole District Municipality's IDP acknowledges problems resulting from the last drought period and proposes 'lessons learnt' with regards to water supply security during drought periods (Amathole District Municipality, 2013). This is a clear indication of 'double-loop learning' which was scored as 'high'. The National Water Resource Strategy (Department of Water Affairs, 2013) proposes to reduce the number of water management areas (WMA) from 19 to 9, which is a clear indication of double-loop learning. 'Discussing doubts' was scored 'high'. Documents as well as interviewees (Interview W1, W2) expressed doubts with regard to uncertainties. 'We do not really know what is to come and what the effects are' (Interview W2). 'Institutional memory' (score: medium), and hence the monitoring and availability of water-related data is a key issue, especially to the bulk water supplier Amatola Water. Amatola Water representatives said that, although the DWA as responsible department needs to realise the true value of it, generally the importance of a monitoring network is acknowledged, also by the public (Interview W1). Information such as the South African Risk and Vulnerability Atlas, IDPs and other documents are available to the public and the Department of Environmental Affairs provides, for example, a leaflet called 'Taking Care of South Africa 'Our Eden'. Join Mr. Mbokodo and Kokwana as they explore climate change' (RSA, n.d.). This leaflet explains climate change and how it could affect people in townships and rural areas, using the format of a comic strip (RSA, n.d.). Turton (2013 p. 76), writing on water governance in South Africa's mining sector, concludes that during the transition period in 1994: 'As each law was repealed, the institutional memory embedded in the massive body of jurisprudence was lost, with nothing to replace it.' The unintended consequence of this was, he says, 'reinforced by the constitutional imperative of cooperative governance as enshrined in Chapter 3 (Co-operative Government), which is interpreted by most government functionaries as meaning that one government department will not challenge another (i.e. cooperation implies non-confrontation)' (Turton, 2013 p. 76).

\section{Room for autonomous change}

The 'room for autonomous change' dimension was scored 'medium'. The 'access to information' is high. All relevant documents are available online and municipalities also provide dam level information online for example. However, given that the study area is a rural area, landline internet access is less available than internet access via mobile phones. This potential could be used more, for instance, for flood warning systems. Whether the climate change response strategies at the provincial and municipal level will be implemented, and, hence, whether the water sector 'acts according to plan', will be shown in the upcoming years as implementation has only just started. However, past experience with other plans or strategies shows very poor compliance that varies across the municipality (Interview W2). The 'capacity to improvise' was scored as 'medium'. This is partly the result of past experiences, especially of (storm) floods. 'Reasonable' stated one interviewee (Interview W3); another said: 'the short term response is good, but not the best' (Interview W2). The representatives from Amatola Water said that they are well prepared for unexpected problems and warn others that are not well prepared. 'But', they added: 'it is not really an integrated system yet' (Interview W1).

\section{Leadership}

Leadership has a 'medium' contribution to adaptive capacity. 'Visionary leadership' exists and a vision is for example clearly expressed in the National Water Resource Strategy (Department of Water Affairs, 2013), but also in other documents such as IDPs. The Eastern Cape's Planning Commission is currently developing a long-term vision for 2030 where environmental and subsequently climate change issues play a major role (Eastern Cape Planning Commission, 2013). However, plans and strategies require implementation which in the past has been rated poorly by the respondents (see 'adaptation belief'). 'Entrepreneurial leadership' was scored as 'high'. For example, the bulk water supplier Amatola Water has a vision of what is necessary to tackle future challenges such as assuring water quality and quantity. Another opportunity is aquaculture as it is envisioned and planned for the Keiskamma River Mouth. 'Collaborative leadership' was rated as 'low'. Although respondents said that they engage with diverse actors (Interviews W1, W2, W3), they also indicated that they have experienced non-cooperative actions from certain actors and parties (Interview W1). The actor spectrum is wide but, as with visionary leadership, mainstreaming climate change within and across governmental departments is envisioned but has yet to be implemented.

\section{Resources}

Resources make a low contribution to adaptive capacity. The lack of 'financial resources' scored very low. A lack of financial resources is always among the first barriers mentioned when asked about the feasibility of adaptation measures (Grecksch, 2013). The two experts from Amatola Water said that if they had more money for monitoring points they could easily improve in this regard. 'The DWA as responsible department needs to realise the true value of a larger monitoring 
network' (Interview W1). They also mentioned that the people who allocate the money should change to people with better water-related knowledge and described it as a situation of technocrats versus politicians. Another interviewee stated that a lot of money is wasted and should be used more efficiently (Interview W2). In terms of 'authority' it is not so much the lack of political will to implement adaptation measures, but the lack of problem awareness and skills to fully understand the issue which led to a 'medium' score. Every expert mentioned problems regarding 'human resources', whether it is understaffing, lack of skills or lack of capacity. 'It is not always the people with the right skills; you need to know though what to prepare for', commented a respondent (Interview W1). Respondents also mentioned that relevant actors did not show up for meetings (Interview W1, W2). The reduction of WMAs from 19 to 9, as foreseen in the National Water Resource Strategy, is one attempt to tackle this issue and improve management.

\section{Fair governance}

Fair governance was scored 'medium'. 'Legitimacy' was scored as 'medium'. The water governance system is currently undergoing change. The number of WMAs is being reduced, legislation will be merged and the DWA has defined its new function in the latest National Water Resource Strategy (Department of Water Affairs, 2013).

'Equity' was scored 'very low'. It is an important topic in South Africa given the country's history. During Apartheid people were relocated, the results of which are still visible. Service delivery - access to basic services such as electricity, water and health, is thus a priority for every municipality. Access to water, enshrined in the country's Constitution, is distributed highly unevenly and is a result of Apartheid policy (Muller et al., 2009; Schreiner, 2009; Smith, 2009; Van Koppen, 2009). In a press statement regarding the National Water Policy Review, the access to free basic water supply (25 litres per day per capita) is emphasised as a key policy position (Department of Water Affairs, 2013). For instance, Van Koppen et al. (2009) point out that the clash between urban water demand and rural water demand is larger than in the 1970s. Sustaining livelihoods in rural areas could become a problem as heat endangers crops, and diseases (rift valley fever) endanger cattle (Interview W2). WUAs and catchment management agencies (CMAs) were meant to be inclusive instruments but have failed, since only two WUAs are in operation (Bourblanc, 2012; Department of Water Affairs, 2013; Kapfudzaruwa et al., 2009; Kemerink et al., 2013; Muller, et al., 2009). Kemerink et al. (2013) show that WUAs favour White commercial farmers with long experience in water governance but neglect the fuzzy organisational structures and differing normative settings in former homelands.

Since climate change and climate change adaptation are mentioned, or even have a dedicated chapter, in all of the documents examined, the score for 'responsiveness' in the study region was 'medium'. Climate change is acknowledged and identified as one of the most important topics. Plans are regularly updated and, for example, the Eastern Cape Planning Commission's Vision 2030 process is meant to be inclusive and collaborative. 'Accountability' was scored as 'medium'. Institutional challenges, i.e., governance failures, have been identified as crucial by the Eastern Cape Planning Commission's Diagnostic Report on Environmental Sustainability in the Eastern Cape (Eastern Cape Planning Commission, 2013). The future changes to water governance as described in the National Water Resource Strategy
(Department of Water Affairs, 2013) should also help foster accountability but have yet to be implemented.

\section{Adaptation motivation}

Adaptation motivation describes an expert valuation of the importance of climate change. All analysed documents and literature emphasise the importance of climate change and have separate chapters on climate change (adaptation). The interviewed experts also stressed the great importance of the issue (Interview W2, W3): 'Climate change is a hot topic, we are aware of it, but it is not a primary driver' (Interview W2). Overall, adaptation motivation is 'medium' in the study area.

\section{Adaptation belief}

Adaptation belief is the assessment by experts of the practicability of adaptation measures. Only if key actors are convinced of the success of adaptation will it also be possible to activate the other elements of adaptive capacity. The adaptation belief in the study area is 'low'. Most adaptation measures were seen as difficult or very difficult to implement. A lack of financial resources and lack of skills, but also missing problem awareness, were named by the experts (Interview W1, W2). One expert stated: 'This issue (i.e. legislation needs to be enhanced with more effective disincentives so as to ensure behaviour change in a vulnerable population) is about getting the society to change. It is about their lethargy and not the legislation. It is my impression that in South Africa there is general lethargy about avoiding a known risk. It is similar to the lethargy shown by the population to the devastating impacts of HIV/AIDS' (Interview W3). On the issue of sea-level rise, coastal erosion and set-back lines in future planning, one expert expects opposition from property owners as coastal property, which is more susceptible to the projected impacts of climate change, is valued higher than property inland (Interview W2). Amatola Water representatives said that vandalism is also a barrier as they have experienced monitoring stations being stolen or damaged (Interview W1).

\section{SUMMARY}

In summary, the adaptive capacity of water governance in the study area is 'medium' (score: 0.58). It is important though to take a closer look at each dimension and criterion, to discover strengths and weaknesses. Climate change adaptation in the sector plays a 'medium' role and most experts are aware of the topic. Hence it is important to stress the benefits of climate change adaptation such as improving livelihoods and creating employment through the implementation of adaptation measures. Worth mentioning in a positive light are the dimensions 'variety', 'learning capacity' and 'room for autonomous change'. The legislative basis is good but successful implementation requires problem awareness, skills and good coordination within municipalities, and also across the three tiers of government in South Africa. One expert spoke of a dysfunctional government and said that 'they don't know what they are doing' and 'there is a lot of talking' (Interview W2). Claassen (2013) underlines this view and concludes that implementing progressive legislation is challenged by a shortage of skilled people, weaknesses in management instruments, difficulties in finding a balance between the role of the state and other institutions, and the effective function of networks. 


\section{RECOMMENDATIONS}

As indicated in the introduction, climate change adaptation strategies need to be tailor-made with respect to local ecological, economic and social characteristics. The National Water Act (RSA, 1998) and the National Water Resource Strategy (Department of Water Affairs, 2013) provide a good basis to start with. Regional and especially local climate data and vulnerability analyses are necessary in order to develop adaptation strategies. Based on the results, the following key recommendations for water governance with regard to climate change adaptation, are suggested:

- Improve coordination across governmental levels and sectors, and within municipalities. Water is a multi-level problem and it must be clearly defined which governmental tier has which role and function, and it is vital to include experts from neighbouring policy fields such as agriculture, forestry and spatial planning.

- Raise awareness among decision makers and the public by informing them about possible climate change effects and possible adaptation measures. Awareness must also be raised in terms of the multiple dimensions of water governance; not only technical and economic but also social and ecological issues linked to water governance.

- Reduce the lack of political will and raise the belief in successful implementation of adaptation measures by stressing their importance and long-term benefits. All interviewed experts complained about the lack of financial resources to implement measures and the lack of political will to overcome this.

- Overcome lack of skills and lack of capacity among decision-makers by either employing more people with waterrelated knowledge or by providing compulsory staff education. All analysed documents and interviewees expressed the need for stronger institutions and better institutional governance.

- Build upon and further improve public participation, which is the basis for improved legitimacy and acceptance. With regard to equity issues, it is also important to include societal groups that are less well represented and organised such as historically disadvantaged people. In addition, regenerate and incorporate traditional water knowledge, especially in former homelands (Kapfudzaruwa, et al., 2009).

- Embrace the opportunities of climate change. Implementing so called no-regret measures, for example restoring natural river beds, could have a positive effect from an ecological and economic point of view because it can create jobs in the restoring phase and in maintenance afterwards.

\section{CONCLUSIONS}

The predominant objective was to assess the adaptive capacity of water governance in the study region. The conclusion drawn is that the assessment revealed a 'medium' adaptive capacity. Despite this neither positive nor negative result, weaknesses as well as strengths could be found in the analysis. On the positive side, it is worth mentioning that climate change as a topic has entered almost every analysed document from the DWA to LMs. This means a basic awareness has been established, especially among those professionally involved in water governance.
Water governance poses a special challenge because water is a complex and cross-sectoral area which permeates into other affected areas (see also Edelenbos et al., 2013). Climate change may exacerbate existing challenges in the study region such as high unemployment, land-use change and, most of all, governance failures. Droughts and floods in recent years demonstrated the weaknesses of the water resource governance system, which include a lack of awareness, coordination, cooperation, and financial resources, but also of human resources: 'it is important that councillors have a clear understanding of the implications and opportunities associated with climate change. Without council support, climate change response is unlikely to be taken forward sufficiently. It is vital that a dedicated councillor awareness programme be developed' (Amathole District Municipality, 2011 p. 51).

The recommendations indicate the usefulness of the Adaptive Capacity Wheel and have been proven and discussed elsewhere (Grecksch, 2013). The tool is highly communicative and can be used to understand the adaptive capacity of water governance and develop recommendations to improve it (Van den Brink et al., 2011). The 'traffic light system' is a useful way to present the strengths (green) and weaknesses (red) of a relevant policy field to stakeholders and decision makers. This is especially important given that the overall 'medium' adaptive capacity. The ACW is a useful heuristic tool to assess adaptive capacity in 'governance systems', especially by addressing issues of social fairness, learning and the dimensions of adaptation motivation and adaptation belief. The ACW sheds light on social dimensions of adaptive capacity which have so far been neglected in studies on climate change vulnerability.

\section{ACKNOWLEDGMENTS}

This research was funded by the German Academic Exchange Service (DAAD) and the project 'Clim-A-Net. The North-South Network on Climate Proofing of Vulnerable Regions'. I would like to especially thank all interviewed experts.

\section{REFERENCES}

AMATHOLE DISTRICT MUNICIPALITY (2011) Amathole District Municipality Climate Change Vulnerability Assessment and Response Framework Final. Land Housing and Economic Development Environmental Units, Amathole District Municipality, East London.

AMATHOLE DISTRICT MUNICIPALITY (2013) 2013-2014 Integrated Development Plan. Amathole District Municipality, East London.

BOURBLANC M (2012) Transforming water resources management in South Africa. 'Catchment Management Agencies' and the ideal democratic development. J. Int. Dev. 24 (5) 637-648.

CLAASSEN M (2013) Integrated water resource management in South Africa. Int. J. Water Gov. 1 (3-4).

CONCA K (2006) Governing Water. Contentious Transnational Politics and Global Institution Building. MIT Press, Cambridge, MA.

DEPARTMENT OF ENVIRONMENTAL AFFAIRS (2011) Governance of climate change in South Africa. Department of Environmental Affairs, Republic of South Africa, Pretoria.

DEPARTMENT OF SCIENCE AND TECHNOLOGY (2010) South African Risk and Vulnerability Atlas. Department of Science and Technology, Republic of South Africa, Pretoria.

DEPARTMENT OF WATER AFFAIRS (2013) National Water Resource Strategy. Water for an Equitable and Sustainable Future. June 2013 Second Edition. Department of Water Affairs, Pretoria. 
DEPARTMENT OF WATER AFFAIRS (2013) Statement by Minister of Water and Environmental Affairs Mrs Edna Molewa. Media Briefing at GCIS Offices at Hatfield, Pretoria. Department of Water Affairs, Pretoria.

DEPARTMENT OF WATER AFFAIRS AND FORESTRY (2006) Eastern Cape Provincial Water Sector Plan 2007/08 to 2011/12. Draft 1. Department of Water Affairs and Forestry, Pretoria.

EASTERN CAPE DEPARTMENT OF ECONOMIC DEVELOPMENT AND ENVIRONMENTAL AFFAIRS (2011) Eastern Cape Climate Change Response Strategy. Eastern Cape Provincial Government, Bisho.

EASTERN CAPE PLANNING COMMISSION (2013) Eastern Cape Planning Commission Vision 2030. A Diagnostic Report on Environmental Sustainability in the Eastern Cape. Eastern Cape Provincial Planning and Treasury, Bisho.

EDELENBOS J and TEISMAN G (2013) Water governance capacity: The art of dealing with a multiplicity of levels, sectors and domains. Int. J. Water Gov. 1 (1-2) 89-108.

FOWLER FJ and MANGIONE TW (1990) Standardized Survey Interviewing. Minimizing Interviewer-Related Error. Sage, Newbury Park.

GRECKSCH K (2013) Adaptive capacity and regional water governance in north-western Germany. Water Polic. (15) 794-815.

GROTHMANN T (2005) Klimawandel, Wetterextreme und private Schadensprävention. Entwicklung Überprüfung und praktische Anwendbarkeit. Dissertation, Universität Magdeburg.

GROTHMANN T, GRECKSCH K, WINGES M and SIEBENHÜNER B (2013) Assessing institutional capacities to adapt to climate change: integrating psychological dimensions in the Adaptive Capacity Wheel. Nat. Hazards Earth Syst. Sci. 13 (12) 3369-3384.

GROTHMANN T and PATT A (2005) Adaptive capacity and human cognition. The process of individual adaptation to climate change. Glob. Environ. Change 15 (3) 199-213.

GROTHMANN T, SIEBENHÜNER B, WINGES M, GRECKSCH K, GARRELTS H and FLITNER M (2011) Social learning - integrating perspectives from political sciences and psychology for understanding capacities to adapt to climate change. In: ESEE Conference, 14-17 June 2011, Istanbul.

GUPTA J, TERMEER C, KLOSTERMANN J, MEIJERINK S, VAN DEN BRINK M, JONG P, NOOTEBOOM S and BERGSMA E (2010) The Adaptive Capacity Wheel: a method to assess the inherent characteristics of institutions to enable the adaptive capacity of society. Environ. Sci. Polic. 13 (2010) 459-471.

GUPTA J, TERMEER K, KLOSTERMANN J, MEIJERINK S, VAN DEN BRINK M, JONG P and NOOTEBOOM S (2008) Institutions for Climate Change. A Method to Assess the Inherent Characteristics of Institutions to Enable the Adaptive Capacity of Society. VU Amsterdam, Institute for Environmental Studies, Amsterdam.

HUITEMA D and MEIJERINK S (eds.) (2009) Water Policy Entrepreneurs. A Research Companion to Water Transitions around the Globe. Edward Elgar, Cheltenham.

HUNTJENS P, LEBEL L, PAHL-WOSTL C, CAMKIN J, SCHULZE $\mathrm{R}$ and KRANZ N (2012) Institutional design propositions for the governance of adaptation to climate change in the water sector. Glob. Environ. Change 22 (1) 67-81.

IDGEC SCIENTIFIC PLANNING COMMITTEE (1999) Institutional dimensions of global environmental change. In: IHDP Report No. 9. International Human Dimensions Programme on Global Environmental Change (IHDP), Bonn.

IPCC (INTERGOVERNMENTAL PANEL ON CLIMATE CHANGE) (2007) Climate Change 2007: Impacts, Adaptation and Vulnerability. Contribution of Working Group II to the Fourth Assessment Report of the Intergovernmental Panel on Climate Change. Cambridge University Press, Cambridge.

KAPFUDZARUWA F and SOWMAN M (2009) Is there a role for traditional governance systems in South Africa's new water management regime? Water SA 35 683-692.

KEMERINK JS, MÉNDEZ LE, AHLERS R, WASTER P and VAN DER ZAAG P (2013) The question of inclusion and representation in rural South Africa: challenging the concept of water user associations as a vehicle for transformation. Water Polic. 15 (2) 243-257.

MADZWAMUSE M (2010) Climate Change Vulnerability and
Adaptation Preparedness in South Africa. Heinrich Böll Foundation, Cape Town.

MAYRING P (2008) Qualitative Inhaltsanalyse. Grundlagen und Techniken. Beltz, Weinheim.

MERTON RK and KENDALL PL (1946) The focussed interview. Am. J. Sociol. 51 541-557.

MEUSER M and NAGEL U (1991) ExpertInneninterviews - vielfach erprobt, wenig bedacht. Ein Beitrag zur qualitativen Methodendiskussion. In: Garz D and K Kraimers (eds) Qualitativempirische Sozialforschung. Westdeutscher Verlag, Opladen. 441-468.

MHANGARA P, KAKEMBO V and LIM KJ (2012) Soil ersosion risk assessment of the Keiskamma catchment, South Africa using GIS and remote sensing. Environ. Earth Sci. 65 (7) 2087- 2102.

MULLER M, SCHREINER B, SMITH L, VAN KOPPEN B, SALLY H, ALIBER M, COUSINS B, TAPELA B, VAN DER MERWE-BOTHA B, KARAR E and PIETERSEN K (2009) Water security in South Africa. Development Planning Division. Working Paper Series No.12. DBSA, Midrand.

NCUBE M, ZIKHALI P and MUSANGO J (2013) The impact of climate variability on water and energy demand: the case of South African local governments. Water Environ. J. 27 29-41.

NGQUSHWA LOCAL MUNICIPALITY (2013) Integrated Development Plan 2013-2014. Ngqushwa Local Municipality, Peddie.

PAHL-WOSTL C (2009) A conceptual framework for analysing adaptive capacity and multi-level learning processes in resource governance regimes. Global Environ. Change 19 (3) 354-365.

RSA (REPUBLIC OF SOUTH AFRICA) (2009) Nation Climate Change Response Policy. Discussion Document for the 2009 National Climate Change Response Policy Development Summit, Gallagher Convention Centre, Midrand, 3-6 March 2009. Republic of South Africa, Pretoria.

RSA (REPUBLIC OF SOUTH AFRICA) (2010) National Climate Change Response. Green Paper. Republic of South Africa, Pretoria.

(1997) Water Services Act (No. 108 of 1997). Republic of South Africa, Cape Town

RSA (REPUBLIC OF SOUTH AFRICA) (2009) National Climate Change Response Policy. Discussion Document for the 2009 National Climate Change Response Policy Development Summit, Gallagher Convention Centre, Midrand, 3-6 March 2009. Republic of South Africa, Pretoria.

RSA (REPUBLIC OF SOUTH AFRICA) (2010) National Climate Change Response. Green Paper. Republic of South Africa, Pretoria.

(1998) National Water Act (Act No 36 of 1998). Republic of South Africa, Cape Town.

RSA (REPUBLIC OF SOUTH AFRICA) (n.d.) Taking Care of South Africa 'Our Eden'. Join Mr. Mbokodo and Kokwana as they explore climate change. Department of Environmental Affairs, Pretoria.

SCHREINER B, PEGRAM G and VON DER HEYDEN C (2009) Reality check on water resources management: Are we doing the right things in the best possible way? Development Planning Division. Working Paper Series No.11. DBSA, Midrand.

SCHULZE RE (2012) A 2011 Perspective on climate change and the South African water sector. WRC Report No. TT 518/12. Water research Commission, Gezina.

SMITH L (2009) Municipal compliance with water services policy: A challenge for water security. Development Planning Division. Working Paper Series No. 10. DBSA, Midrand.

STATISTICS SOUTH AFRICA (2013) Ngqushwa. URL: http://beta2. statssa.gov.za/?page_id=993\&id=ngqushwa-municipality (Accessed 4 September 2013).

STUART-HILL SI and SCHULZE RE (2010) Does South Africa's water law and policy allow for climate change adaptation? Clim. Dev. 2 (2) 128.

TEISMAN G, BUUREN AV, EDELENBOS J and WARNER J (2013) Water governance: Facing the limits of managerialism, determinism, water-centricity, and technocratic problem-solving. Int. J. Water Gov. 1 (1-2) 1-11.

TURTON A (2013) Can water governance deepen democracy in South Africa? Towards a new social charter for mining. Int. J. Water Gov. 1 (1-2) 65-87. 
VAN DEN BRINK M, TERMEER CJAM and MEIJERINK S (2011) Are Dutch water safety institutions prepared for climate change? J. Water Clim. Change 2 (4) 272-287.

VAN KOPPEN B, SALLY H, ALIBER M, COUSINS B and TAPELA B (2009) Water resources management, rural redress and agrarian reform. Development Planning Division. Working Paper Series No.7. DBSA, Midrand.

WEBER EU (1997) Perception and expectation of climate change: precondition for economic and technological adaptation. In:
Bazerman MH, DM Messick, A Tenbrunsel and K Wade-Benzonis (eds) Psychological Perspectives to Environmental and Ethical Issues in Management. Jossey-Bass, San Francisco. 314-341.

WITZEL A (1985) Das problemzentrierte Interview. In: Jüttemann Gs (ed.) Qualitative Forschung in der Psychologie, Beltz, Weinheim. 227-255.

WITZEL A (2000) The problem-centered interview. Forum Qual. Soc Res. 1 (1) Art. 22. 